\title{
Bone Restoration in Diabetic Osteolysis and Therapeutic Targets
}

\author{
Thenmozhi $A^{1 *}$, Nagalakshmi $K^{2}$, Shila $S^{3}$ and Rasappan $\mathrm{P}^{3}$
}

${ }^{1}$ Research and Development Centre, Bharathiar University, Coimbatore, India

${ }^{2}$ Department of Biochemistry, DG Vaishnav College, Chennai, India

${ }^{3}$ VRR Institute of Biomedical Science, Kattupakkam, Chennai, India

\begin{abstract}
Bone, being a key structural support of the body, undergoes dynamic micro structural remodelling all over life to control automatic stress and calcium requirement. Neurovascular, visual, renal complications added with osteopenia and osteoporosis are main unbearable problems in diabetes mellitus (DM). It is clear that hyperglycaemia in diabetes mellitus leads to glucose toxicity which directly suppresses adipogenic delineation of the osteoblast precursors which depreciate bone feature and strength which augment propensity to fracture. A number of risk factors including oxidative stress, apoptosis and abnormal intracellularCa ${ }^{2+}$ metabolism have been postulated to play a function in the inception and progress of osteoporosis within diabetes. This review determines to discuss the most recent findings of mechanisms concerned in the progression of osteoporosis in diabetes. We emphasize the role of signalling molecules in osteoclastogenesis as therapeutic targets in the prevention and treatment of diabetic osteolysis. Increasing validation during the last decade suggests that zinc as neutraceutical suppresses calcium/calcineurin pathway and many compounds are potent inhibitors of osteoclast synthesis by blocking RANKL pathway, an emerging concept that is gaining acceptance. The characteristic of impediment and management of DM-induced osteolysis should be an effective glycaemic control. Hence, we propose to accentuate that Zinc combined with suitable anti-diabetic drugs and inhibitors of osteoclastogenesis may represent a potential therapeutic target in Diabetes mellitus for the prevention, reduction of fracture risk and treatment of osteolysis by suppressing osteoclastogenesis via calcium, calcineurin and RANKL pathway.
\end{abstract}

Keywords: Diabetes; Osteoclast; NF-k B; TRAP; Calcineurin

\section{Introduction}

Diabetes is a collection of metabolic diseases which arises due to defective insulin secretion, insulin resistance, or both and categorized by hyperglycaemia. The chronic hyperglycaemia of diabetes is related with long-term damage, dysfunction, and breakdown of different organs, particularly the eyes, kidneys, nerves, heart, and blood vessels [1]. International Diabetes Federation has estimated the number of diabetic subjects worldwide in 2015 was 415 million and with the present growth rate it is expected rise up to 642 million in 2040 [2]. Metabolic bone diseases, osteoporosis and low-impact fractures have been related with Diabetes. Frequent fall in geriatric subjects has also been reported $[3,4]$. Bone is an extremely active tissue that is subjected to constant remodeling, which is regulated by diverse factors, including cytokines/chemokines, hormones, and mechanical stimuli $[5,6]$. Bone homeostasis is regulated by Linking bone development by osteoblasts and bone resorption by osteoclasts [7]. Osteopenic disorders such as osteoporosis, rheumatoid arthritis, Paget's disease, and lytic bone metastases of malignancies occur due to imbalance in bone resorption by osteoclasts compared to bone construction by osteoblasts [6]. Most drugs used in the healing of osteoporosis are anti-resorptive in action. At present the key pharmacological approaches for management of bone loss are bisphosphonates, oestrogen, and calcitonin. However, there are various side effects from the long-term use of these drugs such as constipation, diarrhoea, tumorigenic, cardiovascular effects, and osteonecrosis of the jaw [8,9].

\section{Literature Review}

Tartrate-resistant acid phosphatase (TRAP)-positive multinucleated cells are produced from Osteoclast precursor cells of monocyte-macrophage lineage. The actin cytoskeleton is streamlined by the multinucleated osteoclasts to attach to the bone surface and to resorb the bone [10]. Macrophage colony- stimulating factor (M-CSF) and receptor activator of nuclear factor-kappa $B$ ligand (RANKL) are the basic cytokines which regulate Osteoclast differentiation. M-CSF is considered as a critical factor in charge for the endurance and rise of osteoclast progenitor cells. Receptor activator of NF- $\kappa$ B (RANK) expression is also induced by M-CSF in osteoclast precursor cells to stimulate efficient reaction to the RANKL-RANK signaling pathways [11-14]. RANKL mediates natural consequence in bone through its exclusive receptor, RANK. The recruitment of tumour necrosis factor receptor-associated factor 6 (TRAF6) is the outcome of binding of RANKL to RANK receptor, which is implicated in the activation of downstream signalling pathways, such as NF- $\kappa$ B, c-Jun N-terminal kinase (JNK), p38, and extracellular signal-regulated kinase (ERK) pathways $[6,15,16]$. RANKL also activates different transcription factors such as NF- $\kappa$ B, microphthalmia transcription factor (MITF), c-Fos, and nuclear factor-activated $\mathrm{T}$ cells $\mathrm{cl}$ (NFATc1), which are in charge for osteoclast segregation. A number of osteoclast specific genes such as TRAP, cathepsin $\mathrm{K}$, calcitonin receptor, and osteoclastassociated receptor (OSCAR) are regulated by NFATc1, a master regulator of osteoclast differentiation, through mutual aid with MITF and c-Fos [16-19]. Hyperglycemia is due to impaired insulin secretion and Beta cell destruction in type1 diabetes mellitus (T1DM) and insulin resistance and inadequate expression of glucose transporter 2 in type 2 diabetes mellitus (T2DM) [20]. Hyper glycaemia also leads to enhanced

*Corresponding author: Thenmozhi A, Research and Development Centre, Bharathiar University, Coimbatore-641046, India, Tel: 0422242 2222; E-mail: jayashreethen@gmail.com

Received: November 22, 2017; Accepted: December 23, 2017; Published: December 30, 2017

Citation: Thenmozhi A, Nagalakshmi K, Shila S, Rasappan P (2017) Bone Restoration in Diabetic Osteolysis and Therapeutic Targets. Diabetes Case Rep 2: 132. doi: $10.4172 / 2572-5629.1000132$

Copyright: (C) 2017 Thenmozhi A, et al. This is an open-access article distributed under the terms of the Creative Commons Attribution License, which permits unrestricted use, distribution, and reproduction in any medium, provided the original author and source are credited. 
activation of the pro-inflammatory transcription factor, nuclear factorkappa B (NF- $\kappa \mathrm{B})$, by protein kinase $\mathrm{C}$ in vitro [21]. The non-enzymatic reaction of glucose and increased fatty acid oxidation forms advanced glycation end products (AGEs). Intracellular hyperglycaemia is the principal initiating condition in the development of both intracellular and extracellular AGEs [22]. AGE binding to AGE receptors can induce the formation of reactive oxygen species, the activation of NF- $\kappa$ B and the production of inflammatory cytokines such as tumour necrosis factor-alpha (TNF- $\alpha$ ) [23]. Oxidative stress is fundamental to the progress of insulin resistance and diabetic complications [24,25]. Oxidative stress plays a significant part in diabetic complications. Hyperglycaemia leads to the over production of super oxides in mitochondria. NF- $\kappa$ B, p38, MAPK and the JNK/SAPK pathway are susceptible to oxidative stress, which is connected to impaired insulin action and the development of the late diabetic complications [26]. As a result of cross-talk between adipose cells, macrophages, and other immune cells that infiltrate the expanding adipose tissue, a most important site, inflammatory mediators are produced [26]. Pro-inflammatory factors, such as tumour necrosis factor (TNF)- $\alpha$, interleukin (IL)-1 $\beta$, IL-6 and IL-18, are augmented in diabetes mellitus which contribute to insulin resistance by both JNK and the inhibitor of nuclear factor kappa-B kinase (IKK $\beta$ )/NF- $\kappa$ B pathway [27]. Enhanced formation of inflammatory cytokines contributes to insulin resistance and the damage of beta cells in the pancreas and is a major aspect in the progress of diabetic complications [28,29].

\section{Impact of Diabetes on Bone and Osteoclasts}

Clinical evidence indicates that bone quality is affected in patients with type 2 diabetes mellitus despite of normal or even high bone mineral density [30]. Dana et al. [30,31] have observed a considerably higher number of multi-nucleated and giant murine osteoclasts in $\mathrm{db} /$ db-derived cultures compared to $\mathrm{C} 57 \mathrm{Bl} / 6$ controls and also determined that analogous phenomenon occurred in human disease. Osteoclasts were derived from peripheral blood monocytes of individuals with and without T2DM. As an indicative of increased osteoclast activity human subjects with T2DM display increased circulating levels of tartrateresistant acid phosphatase in serum due to the diabetic polyol pathway $[29,32,33]$. Anxiety is the cause of prolonged inflammation in diabetes, which may lead to enhanced osteoclastogenesis. Diabetes increases osteoclast development in various conditions like periodontal disease, fracture healing and osteoporosis (Figure 1).

Accelerated bone loss, osteopenia and osteoporosis are in Diabetes mellitus (DM) due to increased osteoclast role and decreased osteoblast function. Macrophage colony stimulating factor (M-CSF), tumour necrosis factor (TNF- $\alpha$ ) and receptor activator of nuclear factor-k B ligand (RANKL) are all Osteoblast-derived activators of osteoclast production and segregation where by Hyperglycaemia induces manufacture of these factors. Hyperglycemia decreases runt related transcription factor (Runx)-2, osteocalcin and osteopontin expressions as a consequence suppression of osteoblast proliferation and function occurs. As indicated by the overexpression of adipocyte differentiation markers, Adipogenic differentiation of mesenchymal stem cells is increased including peroxisome proliferator-activated receptor (PPAR) adipocyte fatty acid binding protein $\left(\mathrm{AP}_{2}\right)$, adipsin and resistin [34].

Poor glycaemic control leads to increased bone resorption and bone loss in subjects with T1DM or T2DM [35]. The higher levels of IL$1 \beta$, TNF- $\alpha$ and prostaglandin E2 in Diabetic animals with periodontitis induce and extend osteoclast mediated resorption [36]. Individuals with T1DM have increased levels of IL-17 and IL-23, which promote osteoclast formation through RANKL. Diabetic rats with periodontitis and T1DM have a 2 to 4 -fold increase in the number of osteoclasts $[37,38]$. Compared to infected normoglycaemic control T2DM rats have a 2 to 4 -fold rise in osteoclasts induced by periodontal infection [39]. Correspondingly, human subjects with T2DM and periodontitis have significantly increased levels of TNF- $\alpha$, IL- $1 \beta$ and IL- 6 connected with delayed inflammation and increased lipid peroxidation and dyslipidaemia $[38,40,41]$. Increased RANKL/OPG ratios and TNF- $\alpha$ levels that contribute to greater bone resorption are observed in diabetes. In human subjects, the ratio of RANKL/OPG and TNF- $\alpha$ levels are increased in inadequately controlled diabetics [42]. In diabetic's fatty

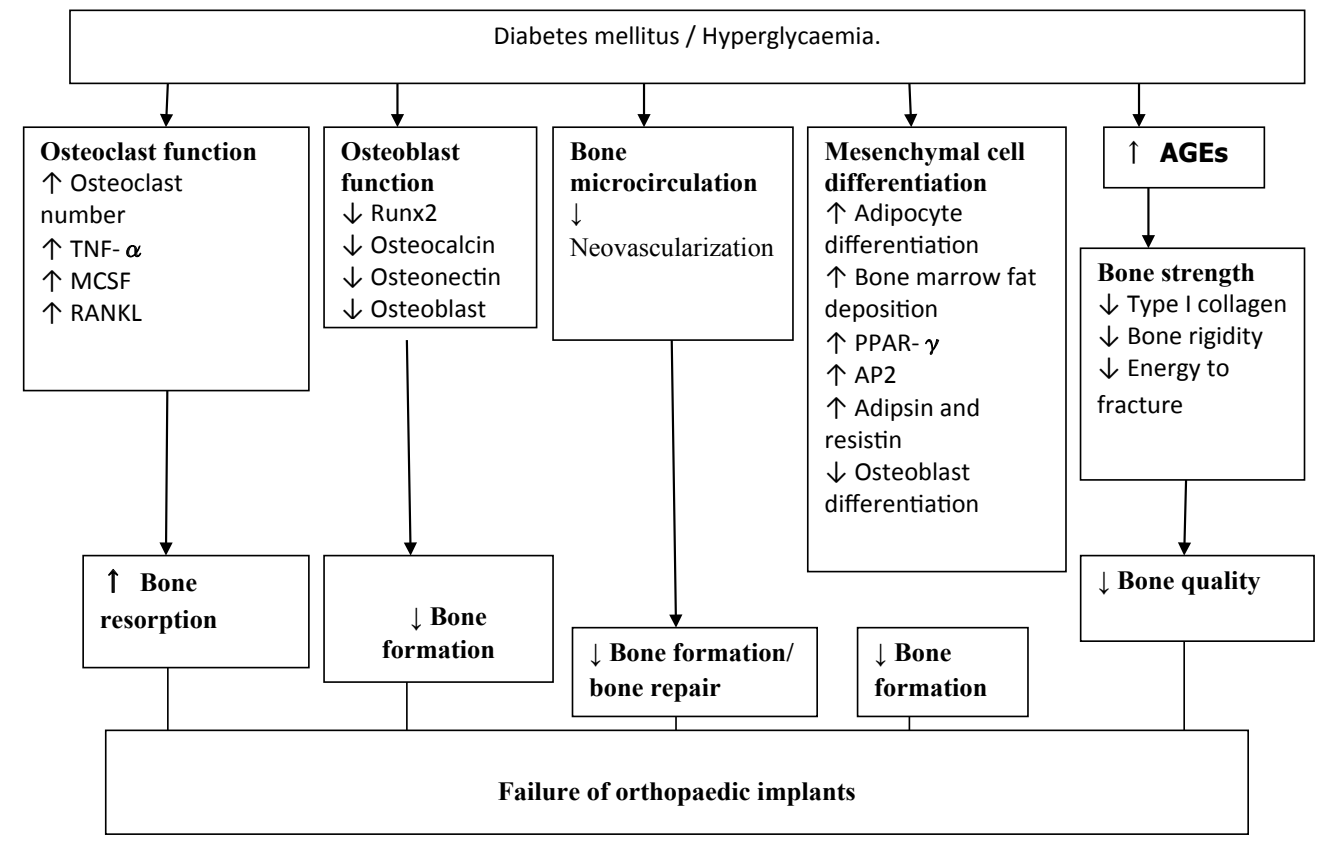

Figure 1: Effects of diabetes mellitus on bone metabolism and bone quality 
acid levels may also add to augmented osteoclastogenesis. Cathepsin $\mathrm{K}$ expression is elevated compared to control group, in streptozotocininduced T1DM rats, representing increased osteoclast activity [43]. In T2DM rats, osteoclastic bone resorption is enhanced compared to normo glycaemic controls [44]. In diabetic mice, macrophage-colony stimulating factor, vascular endothelial growth factor-A, TNF- $\alpha$ and receptor activator of nuclear factor kappa-B ligand (RANKL) are up regulated which can directly proceed osteoclast segregation and activation $[45,46]$. Mitochondrial ROS levels are elevated, in subjects with T2DM, which promote RANKL-mediated osteoclast differentiation and function [47]. Increased fatty acid levels in patients with diabetes mellitus can induce osteoclastogenesis by enhancing TNF- $\alpha$ [48]. Enhanced osteoclast development in reaction to M-CSF and RANKL was exhibited by T2DM mice [32]. AGEs might also enhance osteoclast activity $[31,49,50]$ support the concept that AGEs contribute to osteoclast formation in subjects with diabetes and mice that lack the receptor for AGE, RAGE display increased bone mass and decreased osteoclast numbers compared to wild-type mice [49].

\section{Impact of Diabetes on Osseointegration- is a Contrain- dication in Orthopaedic Prosthesis}

The reaction of parathyroid hormone that regulates the metabolism of phosphorus and calcium is altered by hyperglycaemia which inhibits osteoblast differentiation.

In vitro studies by He et al. support that chronic hyperglycaemia is a stimulus for bone resorption which affects different tissue structures and produces an inflammatory effect. In addition, it produces a harmful consequence on the bone matrix and its system and also affects adherence, growth and amassing of extra-cellular matrix [50]. Mineral homeostasis and production of osteoid has been shown to be evidently diminished in diverse experimental models of diabetes [51]. Diabetes is at present a virtual contraindication for implant management. The investigation of the effect of diabetes on implants has exposed an alteration in bone remodelling processes and deficient mineralization, leading to less bone absorption. The amount of bone formed is analogous when comparing diabetes-induced animals with controls but there is a decline in the bone-implant contact in diabetics $[52,53]$. The decrease in the levels of bone-implant success in diabetics confirms that diabetes reduces bone integration. This situation may be reversed by treating the Failure of orthopaedic hyperglycaemia and maintaining near-normal glucose levels [54]. There is an advanced risk of implant failure in diabetic patients; Ana Mellado et al. have shown that the optimization of glycaemic control improves the degree of osseointegration in the implants [55].

\section{Molecular Targets in the Treatment of Osteolysis}

At present osteoporosis treatment is based on two drug groups, antiresorptive and anabolic agents (Table 1).

The first to be introduced were antiresorptive agents that inhibit bone resorption and generate increased bone mineral density (BMD). Healing with bisphosphonates (BPs), which accelerate the apoptosis of osteoclasts and have shown their efficacy in reducing vertebral and non -vertebral fractures, is the gold standard therapy. Paget's disease of bone, osteolytic bone metastases, and hypercalcemia are also treated with BPs. The chronic use of BPs may be outcome in both osseous and non -osseous adverse effects, and this has led to the search for alternatives [56]. Bisphosphonates inhibit farnesyl pyrophosphate synthase, an important enzyme required for synthesis of isoprenyl and geranylgeranyl, and inhibit prenylation and geranylgeranylation of

\begin{tabular}{|c|c|c|c|}
\hline $\begin{array}{l}\text { S. } \\
\text { No }\end{array}$ & Anti resorptive agents & Molecular targets & $\begin{array}{l}\text { Studies supporting the } \\
\text { targeting compounds }\end{array}$ \\
\hline 1 & PLA & NF-k B, MAPK & {$[68]$} \\
\hline 2 & Melatonin & NF-k B, NFATc1 & [69] \\
\hline 3 & $\begin{array}{l}\text { GNPs-ALD (Gold } \\
\text { nanoparticles and } \\
\text { alendronate) }\end{array}$ & $\begin{array}{l}\text { Farnesyl } \\
\text { pyrophosphate } \\
\text { synthase }\end{array}$ & [61] \\
\hline 4 & Carfilzomib & NF-k B & [66] \\
\hline 5 & Salicortin & $\begin{array}{c}\text { c-Jun N-terminal } \\
\text { kinase, NF-k B, } \\
\text { NFATc1 }\end{array}$ & [67] \\
\hline 6 & Fisetin & TRAP & [65] \\
\hline 7 & Silibinin & TRAP and Cathepsin $\mathrm{K}$ & [64] \\
\hline 8 & Zinc & $\mathrm{Ca}^{2+}-$ Calcineurin & [72] \\
\hline 9 & Phloretin & $\begin{array}{l}\text { RANKL,Cathepsin } \\
\text { K, TRAF6, NF-K B, } \\
\text { NFATc1. }\end{array}$ & [63] \\
\hline 10 & Odanacatib & Cathepsin K & {$[62]$} \\
\hline
\end{tabular}

small G-proteins such as Rac and Rho. This leads to defective actin ring formation at the sealed zone, a subcellular structure essential for bone resorption, and a decrease in bone resorption [57]. The bisphosphonate alendronate reduces the risk of hip, vertebral, and wrist fractures by $35 \%-39 \%$. Zoledronate reduces the risk of hip fractures by $38 \%$ and of vertebral fractures by $62 \%$ [58]. Gold nanoparticles (GNPs) have been reported to influence the restoration of bone tissue in recent years. GNPs-ALD (Gold nanoparticles and alendronate) has the highest inhibitory effects towards osteoclast differentiation of bone marrowderived macrophage [59]. Odanacatib, is a cathepsin K inhibitor, offers theoretical advantages over bisphosphonates. Since it does not reduce the number of osteoclasts and does not alter their function due the mechanism of action which different from that of other anti resorptive agents [60]. Receptor activator of NF- $\kappa$ B ligand (RANKL)-induced formation of multinucleated osteoclasts is inhibited by Phloretin. It also diminished bone resorption area produced during the osteoclast differentiation process. The expression and secretion of cathepsin $\mathrm{K}$ elevated by RANKL was reported to diminish by Sub micro molar quantity of phloretin, being synchronized with inhibition of TRAF6 induction and NF- $\kappa$ B activation. Phloretin also suppressed RANKLinduced activation of nuclear factor of activated T cells c1 (NFATc1) and microphthalmia-associated transcription factor [61]. Zinc inhibits osteoclast differentiation by suppression of Ca2+-Calcineurin-NFATc1 signaling pathway. Zinc is a significant inhibitory modulator throughout osteoclast differentiation that acts on the Ca2+-Calcineurin-NFATc1 signaling pathway. Silibinin is a component Silymarin-rich milk thistle extracts (MTE) which is reported to have enhanced alkaline phosphatase activity of osteoblasts but reduced tartrate-resistant acid phosphatase (TRAP) activity of osteoclasts. Silibinin inhibited femoral bone loss induced by ovariectomy and suppressed femoral TRAP activity and cathepsin $\mathrm{K}$ induction accountable for bone resorption [62,63]. Fisetin, a flavonol found naturally in many fruits and vegetables, suppressed osteoclastogenesis by disturbing receptor activator of nuclear factor (NF) $-\kappa$ B ligand (RANKL)-mediated signalling pathway and demoting osteoclastogenic protein orientation. When fisetin was added to RANKL-exposed macrophages the formation of tartrate-resistance acid phosphatase-positive multinucleated osteoclasts was suppressed [64,65]. Carfilzomib inhibits PTH-induced RANKL expression and its oblique effect on osteoclast genesis by blocking NF- $\kappa \mathrm{B}$ activity in osteoclasts [66]. Salicortin inhibited RANKL-induced c-Jun N-terminal kinase and NF- $\kappa \mathrm{B}$ activation, simultaneous with retarded I $\mathrm{B} \alpha$ phosphorylation and inhibition of p65 nuclear translocation, leading 
to impaired transcription of nuclear factor of activated $\mathrm{T}$ cells $\mathrm{cl}$ (NFATc1) and expression of osteoclast-specific genes [67]. Palmitoleic acid (PLA) inhibits RANKL-induced formation of osteoclasts and interfered with the expression of osteoclast-specific genes in vitro. PLA inhibited the activation of the NF k B and MAPK pathways, offering a possible mechanism of action for its anti-osteoclastogenic effects. PLA further stimulated apoptosis in mature osteoclasts [68]. Melatonin directly suppressed osteoclast delineation through down regulation of NF $\mathrm{k} B$ pathway and following NFATc1 transcription factor induction. Notably, the anti-osteoclastogenic effect of melatonin was supposed to independent of plasma membrane melatonin receptors MT1/MT2. Since melatonin also has been known to increase osteoblast genesis and bone maturation, it might be beneficial for the use of melatonin in bone-resorption associated diseases [69,70].

\section{Discussion and Conclusion}

Hyperglycaemia in diabetic individuals, inhibit osteoblastic activity decreases collagen growth, induces apoptosis in lining cells of bone and increases osteoclastic activity due to continuous inflammatory response. Bisphosphonates are commonly used to decrease bone resorption by inhibiting the activity of osteoclasts. This inhibition is due to many effects such as cytoskeletal disturbance, changing intracellular protein traffic, blocking intracellular signal transduction pathways, and induction of osteoclast apoptosis. By doing this, bisphosphona tes suppress bone-resorption. Amongst bisphosphonates, 4-amino-lhydroxybutylidene-l, 1-bisphosphonate (alendronate, ALD), has been widely used to reduce bone fracture and to cause a continued increase in bone mineral density in postmenopausal osteoporotic subjects. Problems such as suppression of bone formation and jaw necrosis may occur due to excessive inhibition of bone resorption. This is due to difficulty with repairing small bone damage as the bone conversion is inhibited. This is especially prevalent with alveolar bone, which has a ratio of bone conversion 3-10 times higher than other bone tissue in the body. The oral mucosa, which is weaker and thinner than mucosa of other regions, can be negatively affected by the drugs. To avoid these effects, it is necessary to have a drug-delivery system using a carrier to target specific sites. Since no side effects have been reported the efficacy of products like PLA, melatonin, fisetin, silibinin, phloretin, salicortin, cafilzomib and odanacatib with zinc supplementation seem to have a promising role on bone restoration in diabetic osteolysis.

\section{References}

1. ADA American Diabetes Association (2014) Diagnosis and classification of diabetes mellitus. Diabetes Care 37: S81-S90.

2. https://issuu.com/int._diabetes_federation/docs/idf_atlas_2015_uk/13

3. Chau DL, Edelman SV (2002) Osteoporosis and diabetes. Clin Diabetes 20: 153-157.

4. Brown SA, Sharpless JL (2004) Osteoporosis: An under-appreciated complication of diabetes. Clin Diabetes 22: 10-20.

5. Suda T, Takahashi N, Udagawa N, Jimi E, Gillespie MT, et al. (1999) Modulation of osteoclast differentiation and function by the new members of the tumor necrosis factor receptor and ligand families. Endocr Rev 20: 345-357.

6. Teitelbaum SL (2000) Bone resorption by osteoclasts. Science 289:1504-1508

7. Walsh MC, Kim N, Kadono Y, Rho J, Lee SY et al. (2006) Osteoimmunology: Interplay between the immune system and bone metabolism. Annu Rev Immunol 24: 33-63.

8. Miller PD (2008) Anti-resorptives in the management of osteoporosis. Best Pract Res Clin Endocrinol Metab 22: 849-868.

9. Reid IR (2008) Anti-resorptive therapies for osteoporosis Semin. Cell Dev Bio 19: $473-478$
10. Boyle WJ, Simonet WS, Lacey DL (2003) Osteoclast differentiation and activation. Nature 423: 337-342.

11. Wiktor-Jedrzejczak W, Bartocci A, Ferrante AW Jr, Ahmed-Ansari A, Sell KW et al. (1990) Total absence of colony-stimulating factor 1 in the macrophagedeficient osteopetrotic (op/op) mouse. Proc Natl Acad Sci 87: 4828-4832.

12. Yoshida H, Hayashi S, Kunisada T, Ogawa M, Nishikawa S, et al. (1990) The murine mutation osteopetrosis is in the coding region of the macrophage colony stimulating factor gene. Nature 345: 442-444.

13. Kong YY, Feige U, Sarosi I, Bolon B, Tafuri A, et al. (1999) Activated T cells regulate bone loss and joint destruction in adjuvant arthritis through osteoprotegerin ligand. Nature 402: 304-309.

14. Dougall WC, Glaccum M, Charrier K, Rohrbach K, Brasel K, et al. (1999) RANK is essential for osteoclast and lymph node development. Genes Dev 13: 2412 2424.

15. Takayanagi H (2007) Osteoimmunology: Shared mechanisms and crosstalk between the immune and bone systems. Nat Rev Immunol 7: 292-304.

16. Takayanagi H, Kim S, Koga T, Nishina H, Isshiki M, et al. (2002) Induction and activation of the transcription factor NFATc1 (NFAT2) integrate RANKL signaling in terminal differentiation of osteoclasts. Dev Cell 3: 889-901.

17. Matsumoto M, Kogawa M, Wada S, Takayanagi H, Tsujimoto M, et al. (2004) Essential role of p38 mitogen-activated protein kinase in cathepsin $\mathrm{K}$ gene expression during osteoclastogenesis through association of NFATc1 and PU.1. J Biol Chem. 279: 45969-45979.

18. Kim K, Kim JH, Lee J, Mi Jin H, Kim N, et al. (2005) Nuclear factor of activated $\mathrm{T}$ cells $\mathrm{c} 1$ induces osteoclast-associated receptor gene expression during tumor necrosis factor-related activation-induced cytokine-mediated osteoclastogenesis. J Biol Chem 280:35209-35216.

19. Kim Y, Sato K, Asagiri M, Morita I, Soma K, et al. Contribution of nuclear factor of activated T cells $\mathrm{c} 1$ to the transcriptional control of immunoreceptor osteoclastassociated receptor but not triggering receptor expressed by myeloid cells-2 during osteoclastogenesis. J Biol Chem 280: 32905-32913.

20. Unger RH (1991) Diabetic hyperglycemia: Link to impaired glucose transport in pancreatic beta cells. Science 251: 1200-1205.

21. Yerneni KK, Bai W, Khan BV (1999) Hyperglycemia-induced activation of nuclear transcription factor kappaB in vascular smooth muscle cells. Diabetes 48: $855-864$

22. Degenhardt TP, Thorpe SR, Baynes JW (1998) Chemical modification of proteins by methylglyoxal. Cell Mol Biol: Noisy-le-grand 44: 1139-1145.

23. Brownlee M (2001) Biochemistry and molecular cell biology of diabetic complications. Nature 414: 813-820.

24. Evans JL, Goldfine ID, Maddux BA (2002) Oxidative stress and stress-activated signaling pathways: A unifying hypothesis of type 2 diabetes. Endocr Rev 23 599-622.

25. Evans JL, Goldfine ID, Maddux BA (2003) Are oxidative stress-activated signaling pathways mediators of insulin resistance and beta-cell dysfunction? Diabetes 52: 1-8.

26. Lontchi-Yimagou E, Sobngwi E, Matsha TE (2013) Diabetes mellitus and inflammation. Curr Diab Rep 13: 435-444.

27. Johnson DR, O'Connor JC, Satpathy A (2006) Cytokines in type 2 diabetes Vitam Horm 74: 405-441.

28. Nikolajczyk BS, Jagannathan-Bogdan M, Shin H (2011) State of the union between metabolism and the immune system in type 2 diabetes. Genes Immun 12: $239-250$

29. Graves DT, Kayal RA (2018) Diabetic complications and dysregulated innate immunity. Front Biosci 13: 1227-1239.

30. Lecka-Czernik B (2010). Bone loss in diabetes: Use of antidiabetic thiazolidinediones and secondary osteoporosis. Curr Osteoporos 8: 178-184.

31. Catalfamo DL, Britten TM, Storch DI, Calderon NL, Sorenson HL, et al. (2013) Hyperglycemia induced and intrinsic alterations in type 2 diabetes-derived osteoclast function. Oral Dis 19: 303-312.

32. Suzuki K, Kurose T, Takizawa M (2005) Osteoclastic function is accelerated in male patients with type 2 diabetes mellitus: The preventive role of osteoclastogenesis inhibitory factor/osteoprotegerin (OCIF/OPG) on the decrease of bone mineral density. Diabetes Res Clin Pract 68: 117-125. 
33. Takizawa M, Suzuki K, Matsubayashi T (2008) Increased bone resorption may play a crucial role in the occurrence of osteopenia in patients with type 2 diabetes: Possible involvement of accelerated polyol pathway in its pathogenesis. Diabetes Res Clin Pract 82: 119-126.

34. Yamagishi S (2011) Role of advanced glycation end products (AGEs) in osteoporosis in diabetes. Curr Drug Targets 12: 2096-2102.

35. Krakauer JC, McKenna MJ, Buderer NF (1995) Bone loss and bone turnover in diabetes. Diabetes 44: 775-782.

36. Alblowi J, Kayal RA, Siqueria M (2009) High levels of tumor necrosis factoralpha contribute to accelerated loss of cartilage in diabetic fracture healing. Am J Pathol 175: 1574-1585.

37. Silva JA, Ferrucci DL, Peroni LA (2012) Sequential IL-23 and IL-17 and increased Mmp8 and Mmp14 expression characterize the progression of an experimental model of periodontal disease in type 1 diabetes. J Cell Physio 227: $2441-2450$

38. Silva JA, Lopes Ferrucci D, Peroni LA (2012) Periodontal diseaseassociated compensatory expression of osteoprotegerin is lost in type 1 diabetes mellitus and correlates with alveolar bone destruction by regulating osteoclastogenesis. Cells Tissues Organs 196: 137-150.

39. Pacios S, Kang J, Galicia J, Gluck K, Patel H, et al. (2012) Diabetes aggravates periodontitis by limiting repair through enhanced inflammation. Faseb $\mathrm{J} 26$ : 1423-1430.

40. Bastos AS, Graves DT, Loureiro AP, Júnior CR, Abdalla DSP, et al. (2012) Lipid peroxidation is associated with the severity of periodontal disease and local inflammatory markers in patients with type 2 diabetes. J Clinical Endocrinol Metab 97: E1353-1362.

41. Duarte PM, De Oliveira MC, Tambeli CH, Parada CA, Casati MZ, et al. (2007) Overexpression of interleukin-1beta and interleukin- 6 may play a significant role in periodontal breakdown in type 2 diabetic patients. $\mathrm{J}$ Periodontal Res 42:377-381.

42. Santos VR, Lima JA, Goncalves TE, Bastos MF, Figueiredo LC, et al. (2010) Receptor activator of nuclear factor-kappa B ligand/osteoprotegerin ratio in sites of chronic periodontitis of subjects with poorly and well-controlled type 2 diabetes. J Periodontology 81:1455-1465.

43. Alblowi J, Tian C, Siqueira MF, Kayal RA, McKenzie E, et al. (2013) Chemokine expression is upregulated in chondrocytes in diabetic fracture healing. Bone 53: 294-300.

44. Hie M, Shimono M, Fujii K, Tsukamoto I (2007) Increased cathepsin K and tartrate-resistant acid phosphatase expression in bone of streptozotocininduced diabetic rats. Bone 41: 1045-1050.

45. Kayal RA, Tsatsas D, Bauer MA, Allen B, Al-Sebaei MO, et al. (2007) Diminished bone formation during diabetic fracture healing is related to the premature resorption of cartilage associated with increased osteoclast activity. J Bone Miner Res 22: 560-568.

46. Liu R, Bal HS, Desta T, Krothapalli N, Alyassi M, et al. (2006) Diabetes enhances periodontal bone loss through enhanced resorption and diminished bone formation. J Dent Res 85: 510-514.

47. Jeffcoate WJ, Game F, Cavanagh PR (2005) The role of proinflammatory cytokines in the cause of neuropathic osteoarthropathy (acute Charcot foot) in diabetes. Lancet 366: 2058-2061.

48. Ha H, Kwak HB, Lee SW, Hye Mi Jin, Hyun-Man Kim, et al. (2004) Reactive oxygen species mediate RANK signalling in osteoclasts. Exp Cell Res 301: 119-127.

49. Miyata T, Kawai R, Taketomi S (1996) Possible involvement of advanced glycation end-products in bone resorption. Nephrol Dial Transplant 11: 54-57.

50. Weiss RE, Gora A, Nimni ME (1981) Abnormalities in the biosynthesis of cartilage and bone proteoglycans in experimental diabetes. Diabetes 30:670-677.

51. Nyomba BL, Verhaegue J, Tomaste M, Lissens W, Bouillon RB (1989) Bone mineral homeostasis in spontaneously diabetic BB rats. Abnormal vitamin D metabolism and impaired active intestinal calcium absortion. Endocrinology 124:565-572.
52. McCracken M, Lemons JE, Rahemtulla F, Prince CW, Feldman D (2000) Bone response to titanium alloy implants placed in diabetic rats. Int $\mathrm{J}$ Oral Maxillofac Implants 15: 345-354.

53. Nevins ML, Karimbux NY, Weber HP, Giannobile WV, Fiorellini JP (1998) Wound healing around endosseous implants in experimental diabetes. Int $J$ Oral Maxillofac Implants 87: 293.

54. Kopman JA, Kim DM, Rahman SS, Arandia JA, Karimbux NY, et al. (2005) Modulating the effects of diabetes on osseointegration with aminoguanidine and doxycycline. J Periodontol 76: 614-620.

55. Valero AM, García JCF, Ballester AH, Rueda CL (2007) Effects of diabetes on the osseointegration of dental implants Med Oral Patol Oral Cir Bucal 12: E38-43.

56. Cummings SR, Martin JS, McClung MR, Siris ES, Eastell R, et al. (2009) Denosumab for prevention of fractures in postmenopausal women with osteoporosis. New Eng J Med 361: 1914-1914.

57. Li B, Ling Chau JF, Wang X, Leong WF (2011) Bisphosphonates, specific inhibitors of osteoclast function and a class of drugs for osteoporosis therapy. $J$ Cell Biochem 112: 1229-1242.

58. Serrano AJ, Begoña L, Anitua E, Cobos R, Orive G (2013) Systematic review and meta-analysis of the efficacy and safety of alendronate and zoledronate for the treatment of postmenopausal osteoporosis. Gynecol Endocrinol 29: 10051014.

59. Lee D, Heo DN, Kim H, Ko W, Lee SJ, et al. (2016) Inhibition of osteoclast differentiation and bone resorption by bisphosphonate-conjugated gold nanoparticles. Sci Rep 6: 27336.

60. Pérez-Castrillón JL, Pinacho F, De Luis $D$, Lopez-Menendez M, Laita AD (2010) Odanacatib, a new drug for the treatment of osteoporosis: Review of the results in postmenopausal women. J Osteoporosis 2010: 1-5

61. Kim JL, Kang MK, Gong JH, Park SH, Han SY, et al. (2012) Nove antiosteoclastogenic activity of phloretin antagonizing RANKL-induced osteoclast differentiation of murine macrophages. Mol Nutr Food Res 56:12231233

62. Kim J, Kim Y, Kang M, Gong J, Han S, et al. (2013) Antiosteoclastic activity of milk thistle extract after ovariectomy to suppress estrogen deficiency-induced osteoporosis. BioMed Res Int 2013:1-11.

63. Kim YH, Kim JL, Lee EJ, Park SH, Han SY, et al. (2014) Fisetin antagonizes cell fusion, cytoskeletal organization and bone resorption in RANKL-differentiated murine macrophages. J Nutr Biochem 25: 295-303.

64. Yang Y, Blair HC, Shapiro IM, Wang B (2015) The proteasome inhibito carfilzomib suppresses parathyroid hormone-induced osteoclastogenesis through a RANKL-mediated signalling pathway. J Biol Chem 290: 16918 16928.

65. Nie S, Xu J, Zhang C, Xu C, Liu M, et al. (2016) Salicortin inhibits osteoclast differentiation and bone resorption by down-regulating JNK and NF-KB/NFATc1 signalling pathways. Biochem Biophys Res Communications 470: 61-67.

66. Van Heerden B, Kasonga A, Kruger MC, Coetzee M (2017) Palmitoleic acid inhibits RANKL-induced osteoclastogenesis and bone resorption by suppressing NF-kB and MAPK signalling pathways. Nutrients 9: 441.

67. Kim HJ, Kim HJ, Bae M, Kim Y (2017) Suppression of osteoclastogenesis by melatonin: A melatonin receptor-independent action. Int J Mol Sci 18: 1142.

68. Kang J, De Brito Bezerra B, Pacios S, Andriankaja O, Li Y, et al. (2012) Aggregatibacter actinomycetemcomitans infection enhances apoptosis in vivo through a caspase-3-dependent mechanism in experimental periodontitis. Infect Immun 80: 2247-2256.

69. Park KH, Park B, Yoon DS, Kwon S, Shin DM, et al. (2013) Zinc inhibits osteoclast differentiation by suppression of Ca2+-Calcineurin-NFATc1 signalling pathway Park. Cell Comm Signall 11:74.

70. Pacios S, Andriankaja O, Kang J, Alnammary M, Bae J, et al. (2013) Bacteria infection increases periodontal bone loss in diabetic rats through enhanced apoptosis. Am J Pathol 183:1928-1935. 